\title{
Pulling the trigger on the tumor's bodyguards: what puts Tregs out of action?
}

"...in order to pull the trigger on the tumor's bodyguards, one needs molecular markers for specific Treg cell targeting and for prevention of collateral damage."

\section{KEYWORDS: cancer $\approx$ cross-priming $\approx$ FoxP3 $\approx$ immunotherapy $\approx$ regulatory T cell $\|$ Treg - tumor surveillance}

Tumor escape is still a major opponent to the success of many immune interventions in cancer, and a full body of studies has revealed Foxp $3^{+}$ Treg cells to act as bodyguards in the tumor microenvironment, highlighting their critical role in the failure of cancer immunotherapy. As the Treg field becomes more advanced, particularly with regard to the essential function of Treg cells in the maintenance of immunological self-tolerance and autoimmunity [1], recent studies showed compelling evidence conferring a critical role to Treg cells in the tumor's defense against the efforts for an effective cancer immunotherapy $[2,3]$. However, in order to pull the trigger on the tumor's bodyguards, one needs molecular markers for specific Treg cell targeting and for prevention of collateral damage. Therefore, the search is still under way to find a highly specific cell surface marker, paving the way for Treg cell depletion and attenuation of Treg cell suppressive function. In addition, one would like to render effector $T$ cells refractory to Treg cell-mediated suppression. The common goal of all strategies is the attempt to tip the balance towards an effective and specific cancer immunotherapy without inducing unwanted side effects.

High frequencies of Treg cells within the tumor microenvironment have been described in several types of tumors, and have been associated with poor prognosis and reduced survival $[2,3]$, raising the question of whether the tumors recruit Treg cells or generate them from precursors within the tumor microenvironment. Both scenarios seem to be the cause. On the one hand, tumors may induce protection by generating Treg cells from naive $\mathrm{T}$ cells via production of TGF- $\beta$ [3-5], which has been shown to induce the differentiation of naive $\mathrm{T}$ cells into Treg cells [6]. Hence, an attack at TGF- $\beta$ may enhance antitumor immunity. On the other hand, tumors can recruit Treg cells themselves by releasing several chemokines. Tracing and cutting the supply chain for the Treg cells that are recruited by the tumor, for example via $\mathrm{C}-\mathrm{C}$ motif chemokine 22 binding to $\mathrm{C}-\mathrm{C}$ chemokine receptor type 4 [7-9], may be a reasonable approach in cancer immunotherapy and needs to be investigated further. In this context, Treg cells are apparently activated and expanded by both tumor-associated antigens and normal self-antigens that are also expressed by tumor cells. It can be argued, that cancer vaccines that target tumor-associated self-antigens may potentially put the tumor at an advantage by expanding and activating Treg cells. Consequently, it has become of major importance to precisely define and select candidate antigens by assessing not only the activity of wanted vaccine-induced effector $T$ cells, but also the number and suppressive activity of unwanted Treg cells. New insights into the role of Treg cells in metastasis have been reported recently by Tan et al. who describe a significant role for RANKL, produced by Treg cells infiltrating the primary tumors, in the development of metastasis [10]. Consequently, targeting RANKL may be a promising approach in the reduction of metastases in certain cancer types.

\section{"The common goal of all strategies is the attempt to tip the balance towards an effective and specific cancer immunotherapy without inducing unwanted side effects."}

After the first attempts to target Treg cells by administration of cell-depleting anti-CD25 monoclonal antibodies (mAbs) [11], several $\mathrm{mAbs}$ that are specific for cell surface molecules expressed by Treg cells or that are capable of modulating Treg cell function, for example cytotoxic T lymphocyte antigen (CTLA)-4,

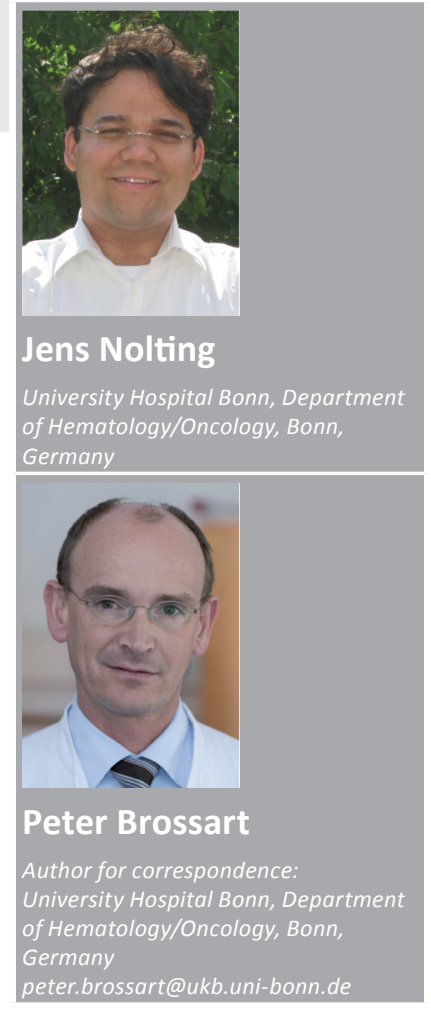


glucocorticoid-induced TNFR-related protein (GITR), Toll-like receptor (TLR), OX40 and folate receptor 4 , are now being investigated. One of the major obstacles for specific Treg cell depletion is the number of overlapping expression patterns of cell surface markers such as CD25, CTLA-4, GITR and OX40 with effector $\mathrm{T}$ cells, owing to the activated phenotype of both Treg cells and effector T cells. Consequently, putting the bodyguards in the line of fire for an aimed shot is a challenging and intricate mission.

$$
\begin{aligned}
& \text { "... designing a combination therapy } \\
& \text { that targets a variety of molecules } \\
& \text { expressed in antigen-presenting cells, } \\
& \text { effector T cells and Treg cells might allow } \\
& \text { to overcome the tumor escape." }
\end{aligned}
$$

We learned that combinations of mAbs that are able to modulate Treg cell functions can synergistically enhance antitumor activity and are more effective than a single mAb therapy [12] Hence, designing a combination therapy that targets a variety of molecules expressed in antigen-presenting cells, effector $\mathrm{T}$ cells and Treg cells might allow to overcome the tumor escape. For example, the combination of Treg cell depletion and adoptive transfer of antigen-specific cytotoxic $\mathrm{T}$ cells may be a reasonable approach in cancer treatments that needs to be further explored [13]. Furthermore, it has been shown that synergistic antitumor effects can be achieved by the combination of anti-CTLA-4 blocking $\mathrm{mAb}$ and anti-GITR agonistic mAb compared with either antibody therapy alone [12]. Based on our current knowledge of possible, but partially poorly understood, contact-dependent and -independent suppression mechanisms [14], the list of potential molecular targets of Treg function can be further extended by, among others, perforin/ granzyme [15,16], intracellular cyclic AMP [17], adenosine catalyzed by CD39 and CD173 [18], and cytokines such as IL-10 [19], IL-35 [20] and, as previously mentioned, TGF- $\beta$.

\section{Switching the spotlight on TLR signals}

They have been proven to interfere with the suppressive activity of Treg cells by partially IL-6dependent mechanisms [21] and, moreover, they are able to stimulate IL-2 secretion by effector $\mathrm{T}$ cells, thus, making effector $\mathrm{T}$ cells less susceptible for Treg cell-mediated suppression [22]. A recent report challenged the idea of Treg cells as exclusive bodyguards who offer their work solely under the conditions determined by the tumor: Sharma et al. demonstrated that TLR stimulation induces reprogrammed Treg cells that promote cross-priming of $\mathrm{CD}^{+}{ }^{+} \mathrm{T}$ cells, which enhances T-cell effector responses [23]. Consistent with previous reports, local production of IL- 6 provides a central inflammatory signal that triggers the conversion of Treg cells into reprogrammed Treg cells. In this context, the authors demonstrated that, upon TLR stimulation, reprogrammed Treg cells may amplify CD8 ${ }^{+} \mathrm{T}$-cell responses, demonstrating that Treg cells can unexpectedly support the eradication of the tumor under certain conditions [23]. At first glance, these results seem to be somewhat at odds with the idea that it is primarily the lack of Treg cells that gives access to an effective cancer immunotherapy, allowing us to reconsider the role of Treg cells and their plasticity in this setting. Sharma et al. were able to offer deeper insight into the still little elucidated role of Treg cells in cross-priming, increasing interest in further investigation in this field.

Taking advantage of the discussed combinatory strategies might enable us to get rid of the tumor's protecting bodyguards or win them for our team, and clear the entrance for effective cancer immunotherapy in clinical settings.

\section{Financial \& competing interests disclosure}

The authors have no relevant affiliations or financial involvement with any organization or entity with a financial interest in or financial conflict with the subject matter or materials discussed in the manuscript. This includes employment, consultancies, honoraria, stock ownership or options, expert testimony, grants or patents received or pending, or royalties.

No writing assistance was utilized in the production of this manuscript.

\section{Bibliography}

1 Daniel C, Nolting J, von Boehmer H: Mechanisms of self-nonself discrimination and possible clinical relevance. Immunotherapy 1, 631-644 (2009).

2 Dougan M, Dranoff G: Immune therapy for cancer. Ann. Rev. Immunol. 27, 83-117 (2009).

3 Curiel TJ: Tregs and rethinking cancer immunotherapy. J. Clin. Investig. 117, 1167-1174 (2007).

4 Ghiringhelli F, Puig PE, Roux S et al:: Tumor cells convert immature myeloid dendritic cells into TGF- $\beta$-secreting cells inducing
$\mathrm{CD} 4{ }^{+} \mathrm{CD} 25^{+}$regulatory $\mathrm{T}$ cell proliferation. J. Exp. Med. 202, 919-929 (2005).

5 Liu VC, Wong LY, Jang T et al:: Tumor evasion of the immune system by converting $\mathrm{CD} 4{ }^{+} \mathrm{CD} 25^{-} \mathrm{T}$ cells into $\mathrm{CD} 4{ }^{+} \mathrm{CD} 25^{+}$ $\mathrm{T}$ regulatory cells: role of tumor-derived TGF- $\beta$. J. Immunol. 178, 2883-2892 (2007).

6 Chen W, Jin W, Hardegen $\mathrm{N}$ et al.: Conversion of peripheral $\mathrm{CD} 4{ }^{+} \mathrm{CD} 25^{-}$naive $\mathrm{T}$ cells to $\mathrm{CD} 4{ }^{+} \mathrm{CD} 25^{+}$regulatory $\mathrm{T}$ cells by TGF- $\beta$ induction of transcription factor Foxp3. J. Exp. Med. 198, 1875-1886 (2003). 
7 Gobert M, Treilleux I, Bendriss-Vermare N et al:: Regulatory $\mathrm{T}$ cells recruited through CCL22/CCR 4 are selectively activated in lymphoid infiltrates surrounding primary breast tumors and lead to an adverse clinical outcome. Cancer Res. 69, 2000-2009 (2009).

8 Curiel TJ, Coukos G, Zou L et al.: Specific recruitment of regulatory $\mathrm{T}$ cells in ovarian carcinoma fosters immune privilege and predicts reduced survival. Nat. Med. 10, 942-949 (2004).

9 Iellem A, Mariani M, Lang R et al.: Unique chemotactic response profile and specific expression of chemokine receptors CCR 4 and CCR 8 by $\mathrm{CD} 4{ }^{+} \mathrm{CD} 25^{+}$regulatory $\mathrm{T}$ cells. J. Exp. Med. 194, 847-853 (2001).

10 Tan W, Zhang W, Strasner A et al: Tumour-infiltrating regulatory $\mathrm{T}$ cells stimulate mammary cancer metastasis through RANKL-RANK signalling. Nature 470, 548-553 (2011).

11 Onizuka S, Tawara I, Shimizu J, Sakaguchi S, Fujita T, Nakayama E: Tumor rejection by in vivo administration of anti-CD25 (interleukin-2 receptor $\alpha$ ) monoclonal antibody. Cancer Res. 59, 3128-3133 (1999).
12 Ko K, Yamazaki S, Nakamura K et al.: Treatment of advanced tumors with agonistic anti-GITR $\mathrm{mAb}$ and its effects on tumorinfiltrating Foxp $3{ }^{+} \mathrm{CD} 25^{+} \mathrm{CD} 4^{+}$regulatory T cells. J. Exp. Med. 202, 885-891 (2005).

13 Ohmura Y, Yoshikawa K, Saga S, Ueda R, Kazaoka Y, Yamada S: Combinations of tumor-specific CD8+ CTLs and anti-CD25 $\mathrm{mAb}$ provide improved immunotherapy. Oncol. Rep. 19, 1265-1270 (2008).

14 Shevach EM: Mechanisms of foxp $3^{+}$ $T$ regulatory cell-mediated suppression. Immunity 30, 636-645 (2009).

15 Gondek DC, Lu LF, Quezada SA, Sakaguchi S, Noelle RJ: Cutting edge: contact-mediated suppression by $\mathrm{CD} 4{ }^{+} \mathrm{CD} 25^{+}$ regulatory cells involves a granzyme B-dependent, perforin-independent mechanism. J. Immunol. 174, 1783-1786 (2005).

16 Cao X, Cai SF, Fehniger TA et al: Granzyme B and perforin are important for regulatory $\mathrm{T}$ cell-mediated suppression of tumor clearance. Immunity 27, 635-646 (2007).

17 Bopp T, Becker C, Klein M et al.: Cyclic adenosine monophosphate is a key component of regulatory $\mathrm{T}$ cell-mediated suppression. J. Exp. Med. 204, 1303-1310 (2007).
18 Deaglio S, Dwyer KM, Gao W et al: Adenosine generation catalyzed by CD39 and CD73 expressed on regulatory $\mathrm{T}$ cells mediates immune suppression. J. Exp. Med. 204, 1257-1265 (2007).

19 Asseman C, Mauze S, Leach MW, Coffman RL, Powrie F: An essential role for interleukin 10 in the function of regulatory $\mathrm{T}$ cells that inhibit intestinal inflammation. J. Exp. Med. 190, 995-1004 (1999).

20 Collison LW, Workman CJ, Kuo TT et al.: The inhibitory cytokine IL-35 contributes to regulatory T-cell function. Nature 450, 566-569 (2007).

21 Pasare C, Medzhitov R: Toll pathwaydependent blockade of $\mathrm{CD} 4^{+} \mathrm{CD} 25^{+}$ $\mathrm{T}$ cell-mediated suppression by dendritic cells. Science (NY) 299, 1033-1036 (2003).

22 Liu H, Komai-Koma M, Xu D, Liew FY: Toll-like receptor 2 signaling modulates the functions of $\mathrm{CD} 4^{+} \mathrm{CD} 25^{+}$regulatory $\mathrm{T}$ cells. Proc. Natl Acad. Sci. USA 103, 7048-7053 (2006).

23 Sharma MD, Hou DY, Baban B et al: : Reprogrammed Foxp $3^{+}$regulatory $\mathrm{T}$ cells provide essential help to support crosspresentation and $\mathrm{CD}^{+} \mathrm{T}$ cell priming in naive mice. Immunity 33, 942-954 (2010). 